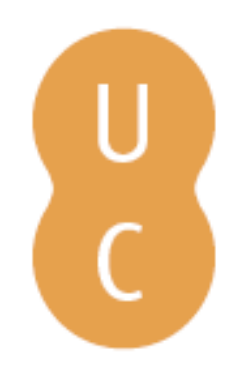

\title{
pombalina
}

\section{Modelação da qualidade da água em lagos vulcânicos: interacção com fluidos de origem magmática}
Autor(es):
Antunes, Paulo; Martins, Gilberto; Ribeiro, Daniel; Cruz, José; Brito, António; Nogueira, Regina

Publicado por: Imprensa da Universidade de Coimbra

URL persistente:

URI:http://hdl.handle.net/10316.2/36294

DOI:

DOI:http://dx.doi.org/10.14195/978-989-26-1009-2_7

Accessed : $\quad$ 26-Apr-2023 14:14:55

A navegação consulta e descarregamento dos títulos inseridos nas Bibliotecas Digitais UC Digitalis, UC Pombalina e UC Impactum, pressupõem a aceitação plena e sem reservas dos Termos e Condições de Uso destas Bibliotecas Digitais, disponíveis em https://digitalis.uc.pt/pt-pt/termos.

Conforme exposto nos referidos Termos e Condições de Uso, o descarregamento de títulos de acesso restrito requer uma licença válida de autorização devendo o utilizador aceder ao(s) documento(s) a partir de um endereço de IP da instituição detentora da supramencionada licença.

Ao utilizador é apenas permitido o descarregamento para uso pessoal, pelo que o emprego do(s) título(s) descarregado(s) para outro fim, designadamente comercial, carece de autorização do respetivo autor ou editor da obra.

Na medida em que todas as obras da UC Digitalis se encontram protegidas pelo Código do Direito de Autor e Direitos Conexos e demais legislação aplicável, toda a cópia, parcial ou total, deste documento, nos casos em que é legalmente admitida, deverá conter ou fazer-se acompanhar por este aviso.

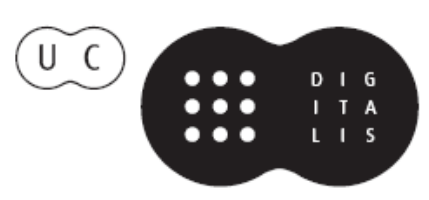




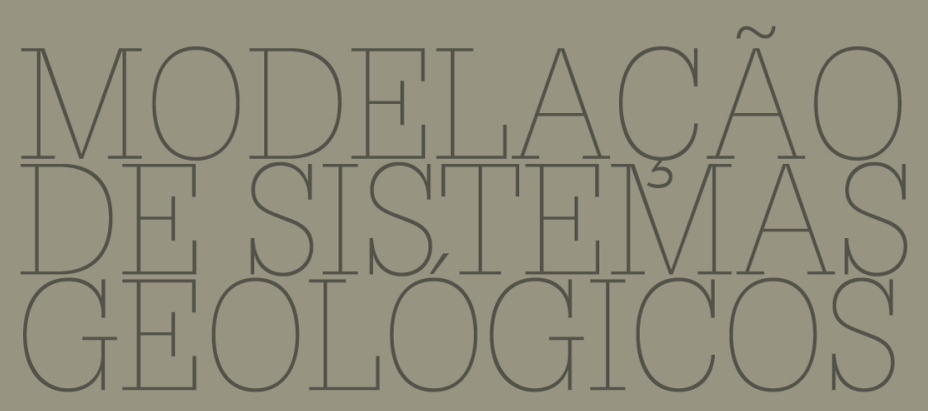

Homenagem ao Professor Doutor Manuel Maria Godinho

L.J.P.F. Neves, A.J.S.C. Pereira,

C.S.R. Gomes, L.C.G. Pereira,

A.O. TAVARES

IMPRENSA DA UNIVERSIDADE DE COIMBRA

CoImBra University Press 


\title{
MODELAÇÃO \\ DE SISTEMAS \\ GEOLÓGICOS
}

Homenagem ao Professor Manuel Maria Godinho

\section{Modelação da qualidade da água em lagos vulcânicos: interacção com fluidos de origem magmática}

\author{
Paulo Antunes ${ }^{1}$; Gilberto Martins ${ }^{2}$; Daniel Ribeiro ${ }^{2}$; José Cruz ${ }^{1}$; António \\ Brito $^{2}$, Regina Nogueira ${ }^{2}$ \\ ${ }^{1}$ Centro de Vulcanologia e Avaliação de Riscos Geológicos, Universidade dos Açores, PORTUGAL, \\ pantunes@uac.pt \\ ${ }^{2}$ IBB - Institute for Biotechnology and Bioengineering, Universidade do Minho, PORTUGAL.
}

Palavras-chave: Lagos vulcânicos, $\mathrm{CO}_{2}$, fluidos vulcânicos

\section{Resumo}

O modelo utilizado decorre do esforço desenvolvido no sentido de se compreender a dinâmica entre a qualidade da água dos lagos do arquipélago dos Açores e a eventual interacção com fluidos de origem vulcânica nos sistemas lacustres localizados no interior de vulcões activos. Com o intuito de utilizar estes sistemas aquáticos na monitorização vulcânica, recorreu-se ao modelo DYRESM CAEDYM para se perceber uma entrada ocasional de carbono inorgânico de origem vulcânico, na Lagoa Verde das Sete Cidades. O resultado do modelo permitiu constatar que, actualmente, a concentração do carbono inorgânico dissolvido na água da Lagoa Verde é superior ao modelado, sugerindo que este "excesso" de dióxido de carbono seja proveniente de uma entrada no lago de fluidos de origem vulcânica. Também o resultado dos cenários modelados permitiu compreender o comportamento do lago face à entrada de grandes concentrações de carbono neste sistema, resultante de um cenário pré-eruptivo. O modelo é limitado no estudo da Hidrogeoquímica, não sendo possível modelar o contributo de voláteis nos sistemas aquáticos ou tirar qualquer ilação relativamente aos processos de interacção água-rocha, nomeadamente na lixiviação dos metais alcalinos e alcalino-terrosos e do silício. Contudo, para o objectivo proposto, o programa DYRESM-CAEDYM apresenta potencial na aplicação e exploração da monitorização vulcânica, nomeadamente na simulação do input do carbono inorgânico.

Key-words: Volcanic lakes, $\mathrm{CO}_{2}$, Volcanic fluids

\section{Abstract}

The DYRESM_CAEDYM was used for a better understanding of the water environment related to the $\bar{C} \mathrm{O}_{2}$ dynamic in the Azorean lakes, namely, on the Lagoa Verde located in the Sete Cidades volcano. The main goal was the modulation of the volcanic $\mathrm{CO}_{2}$ input on the water lake for a better understanding of the behavior of $\mathrm{CO}_{2}$ equilibrium. The modulation results show a lower dissolved inorganic carbonate (DIC) concentration when compared to the observed data of the last years. The hydrogeochemical studies in this system show a 
volcanic fluids contribution that explained the highest $\mathrm{CO}_{2}$ contribution. The scenarios modulated in Lagoa Verde allowed to understand the behavior of DIC in depth face an preeruptive scenario. Related to hydrogeochemical study, the software is limited and is impossible to modulated the volcanic volatiles contribution and the hydrolyze of rock concerning to the water acidification. However, for the goal proposed the program show a great potential to predict future scenarios face a volcanic input in water lake.

\section{Introdução}

De uma forma geral, a água dos lagos dos Açores, são predominantemente frias, com temperaturas a variar entre os $5,2^{\circ} \mathrm{C}$ e os $23,5^{\circ} \mathrm{C}$ e demonstram uma tipologia cloretada sódica a bicarbonatada sódica (Antunes, 2008).

A Lagoa Verde apresenta uma temperatura da água mínima de $12,7^{\circ} \mathrm{C}$ e máxima de $23,3^{\circ} \mathrm{C}$, entre os anos de 2002 a 2007 , e do tipo cloretada sódica, reflectindo o contributo do transporte de sais de origem marinha através do acarreio atmosférico. $\mathrm{O} \mathrm{pH}$ da água apresenta um intervalo de valores considerável, principalmente no Verão ( $\operatorname{mín} .=6,59 ;$ max. $=9,61$ ). Este facto, advém da estratificação da água de origem térmica, mas também se deve aos processos biológicos relacionados com a eutrofização que se observa neste sistema. A estratificação da água do lago reflecte o aumento da concentração do dióxido de carbono no fundo. O contributo do dióxido de carbono no hipolimnion poderá estar relacionado com outra fonte, além da degradação da matéria orgânica que fica limitada aos processos anaeróbicos, pelo que não será de excluir uma contribuição de origem vulcânica (Antunes 2008).

A aplicação de modelos numéricos relativos à qualidade da água com a perspectiva de gerir os sistemas aquáticos é largamente utilizada em lagos, reservatórios, rios e estuários (Romero et al., 2004; Martins et al., 2008). A necessidade de gerir e, principalmente, de prever cenários relativos à evolução da qualidade da água devido à constante pressão antropogénica sobre os recursos hídricos e, em especial, ao incremento da eutrofização e da poluição dos lagos a nível global, contribuiu, decisivamente, para a evolução dos modelos aplicados nesta vertente de estudo, à qual não é alheio o desenvolvimento e acessibilidade da tecnologia informática (Canfield e Hoyer, 1988; Jørgensen, 1995; Hamilton e Schladow, 1997; Gal et al., 2003; Burger et al., 2008).

A informação obtida pelos modelos acerca de fenómenos complexos e muitas vezes não totalmente assimilados e entendidos pelo ser humano poderá contribuir para uma melhor compreensão, tomada de decisões e respostas, muitas vezes exigidas prontamente, no que diz respeito a 
problemas que poderão ter um grande impacte numa comunidade populacional (Martins et al., 2008).

A escolha do programa de modelação a utilizar na Lagoa Verde, que em conjunto com a Lagoa Azul constituem a designada Lagoa das Sete Cidades, em concreto, na ilha de São Miguel, recaiu sobre o modelo hidrodinâmico DYRESM acoplado ao modelo ecológico CAEDYM (DYRESM_CAEDYM). Este arquétipo apresenta-se como um modelo mais complexo, modelando uma diversidade de parâmetros físicos, biológicos ou químicos, relativamente a outros modelos que se limitam a entradas e saídas. Esta complexidade, relativa à interacção entre atmosfera, coluna de água (incluindo os biotas) e sedimento, permite uma melhor compreensão quanto aos processos físicos, químicos e biológicos que ocorrem nestes sistemas lacustres (Imberger et al., 1978; Hamilton e Schladow, 1997; Hornung, 2002; Balistrieri et al., 2006).

Nesse sentido o presente trabalho teve por objectivo compreender o comportamento da concentração do carbono na água do lago em resultado de uma entrada, deste elemento, de origem vulcânico.

\section{Metodologia}

Para a modelação, foram inicialmente considerados 4 anos (2004 a 2007), período correspondente aos dados recolhidos no campo (Antunes, 2008) e capazes de descrever a dinâmica observada na Lagoa Verde. Para configurar os ficheiros correspondentes ao ano de 2004, utilizaram-se os dados cedidos pela DROTRH e os apresentados por Martins et al. (2008).

Esta metodologia foi possível de desenvolver, na estruturação dos diferentes ficheiros de configuração, devido aos lagos apresentarem características físico-químicas e biológicas cíclicas e estáveis. Deste modo, os ficheiros de configuração utilizados na preparação do modelo são mais robustos, devido à existência de dados de campo mais completos no provimento dos ficheiros relativos aos 366 dias do ano de 2004 e seguintes. Após o modelo ter sido calibrado para este intervalo de tempo, utilizou-se a mesma metodologia na formatação das diferentes extensões para se proceder à execução dos cenários para 10 anos, objectivo final do estudo.

\section{Calibração}

A calibração do modelo foi efectuada para a temperatura, oxigénio dissolvido, $\mathrm{pH}$ e fosfatos. A calibração hidrodinâmica assentou na manipulação dos dados meteorológicos. Este facto contradiz os resultados 
apresentados por outros autores (Imberger e Patterson (1990; Hamilton e Schladow, 1997; Hornung, 2002; Copetti et al., 2006), nomeadamente, no que se refere à resposta do DYRESM em diferentes lagos internacionais e que sempre apresentou resultados congruentes com os registados nas diferentes massas de água, independentemente do objectivo do estudo desenvolvido. No presente estudo, a necessidade de calibração do modelo, relativo à parte hidrodinâmica, deveu-se ao facto de os dados meteorológicos utilizados na configuração do modelo, serem registados, de uma forma geral, por postos hudométricos e estações meteorológicas afastados deste sistema lacustre e muitas vezes localizados a altitudes significativamente mais elevadas. Na figura 1 apresenta-se a comparação entre os resultados simulados para a temperatura e outros dados de campo (Figura 2 e 3).

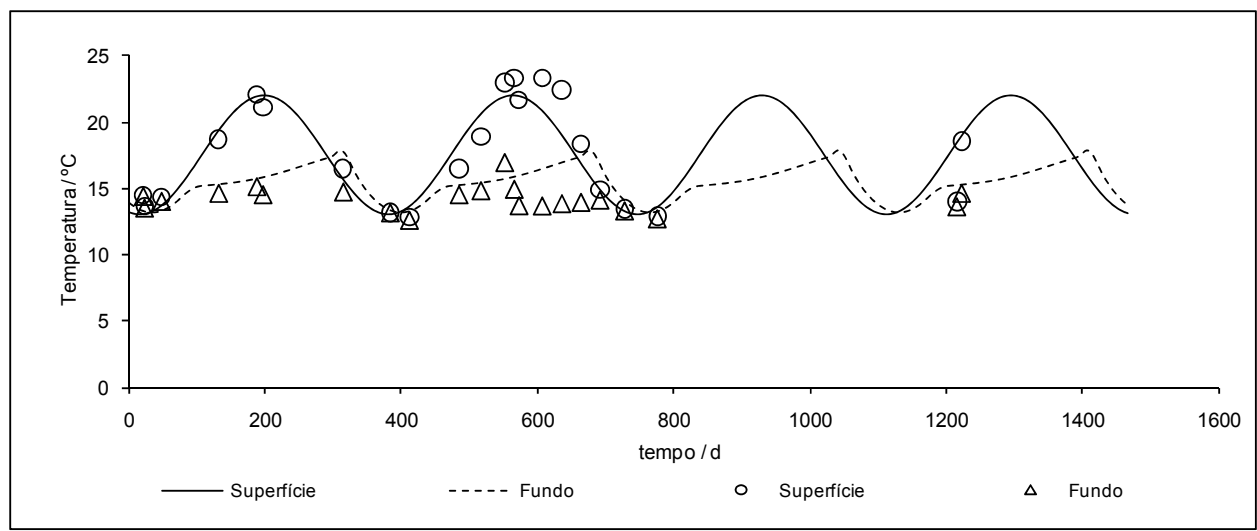

Figura 1. Comparação dos resultados do modelo e os dados de campo relativos à temperatura, após calibração do modelo hidrodinâmico.

A calibração do fitoplâncton não foi efectuada, pois iria exigir uma abordagem diferente ao modelo, quer em número de dados experimentais necessários, bem como no tempo necessário para a sua calibração. Assim, as leituras que são retiradas das presentes simulações são sempre comparativas e apenas reflectem possíveis alterações do estado do sistema. 


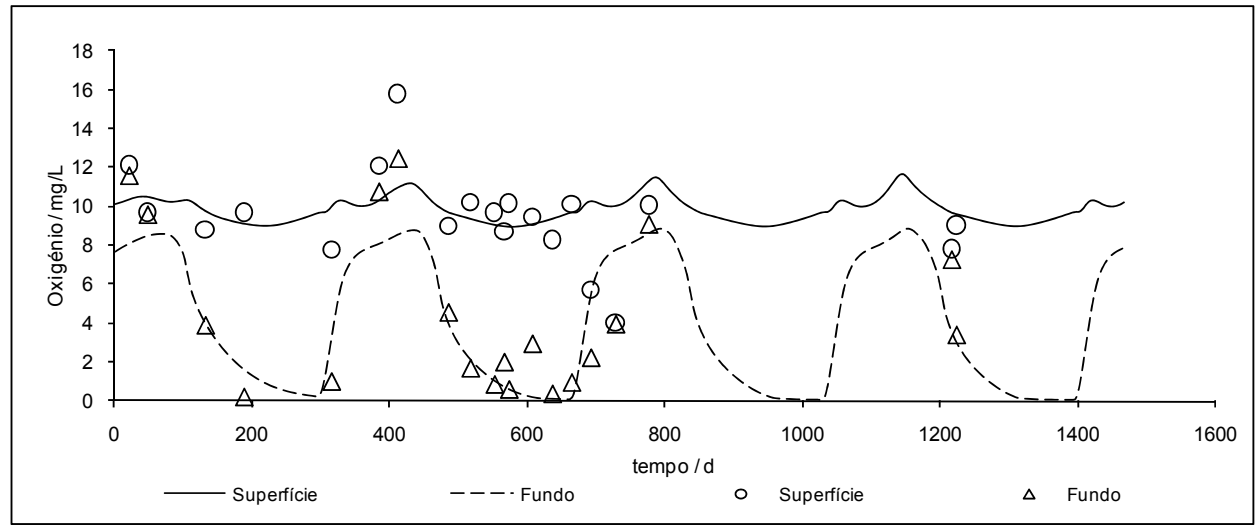

Figura 2. Resultado do $\mathrm{O}_{2}$ simulado pelo modelo (linhas contínuas) e comparado com os dados de campo (pontos).

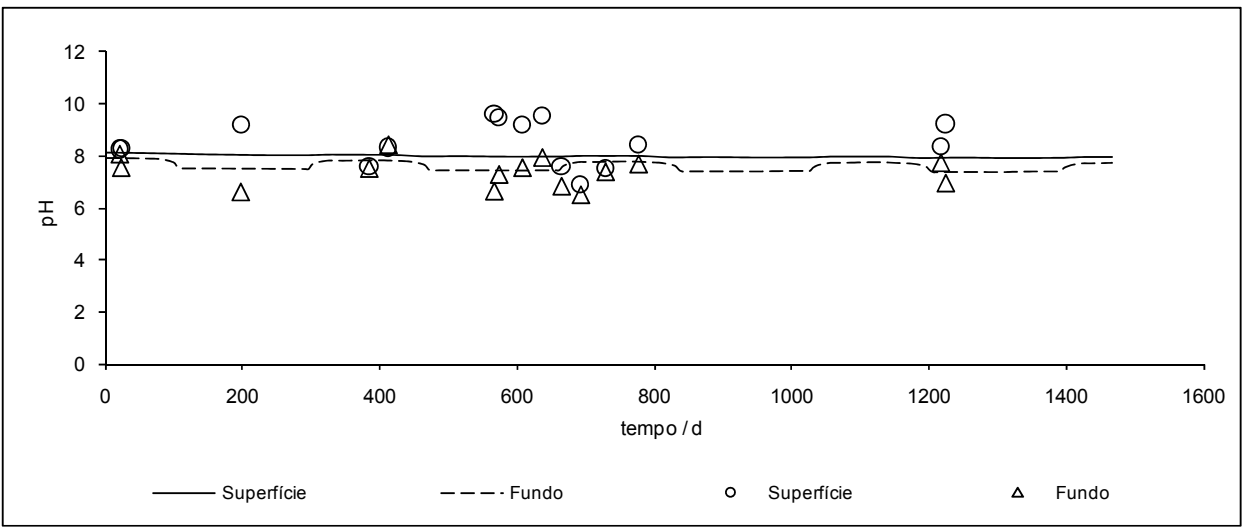

Figura 3. Resultado do pH simulado pelo modelo (linhas continuas) e comparado com os dados de campo (pontos).

\section{Cenários simulados}

Após efectuada a calibração e feita a verificação de todos os ficheiros, foram ensaiados diversos cenários, para um espaço temporal de 10 anos. Escolheu-se o ano de 2004 como início das simulações.

O input de dióxido de carbono no lago foi simulado através da entrada do carbono inorgânico dissolvido (DIC), opção que existe neste modelo através de um caudal de água, configurado para entrar no fundo deste sistema.

Relativamente a este caudal e respectivas concentrações de carbono, consideramo-los relativamente proporcionais $\left(1000 \mathrm{~m}^{3} / \mathrm{d}\right)$ quando comparados com algumas nascentes de água termal e mineral existentes na 
ilha de S. Miguel. Deste modo, tivemos como propósito investigar o comportamento da água dos lagos, na eventualidade de ocorrer a entrada esporádica de fluidos de origem vulcânica e com baixa concentração dos seus elementos nativos. Deste modo, pretende-se verificar se o modelo responde à entrada de caudais com reduzidas concentrações de carbono, atendendo ao volume de água que este sistema lacustre apresenta e identificar, se possível, o tipo de alterações na qualidade da água.

$\mathrm{O}$ input de dióxido de carbono simulado nos diferentes cenários foi efectuado no ano de 2004, início da modelação, através da entrada de um caudal diário de $1000 \mathrm{~m}^{3}$ de água no fundo do lago, com concentrações de $500 \mathrm{mg} / \mathrm{l}, 1000 \mathrm{mg} / \mathrm{l}$ e $2000 \mathrm{mg} / \mathrm{l}$ de carbono inorgânico dissolvido (DIC).

\section{Resultados e Discussão}

O resultado do cenário modelado para as condições naturais do lago apresenta uma diminuição do carbono orgânico dissolvido ao longo do tempo (Figura 4).

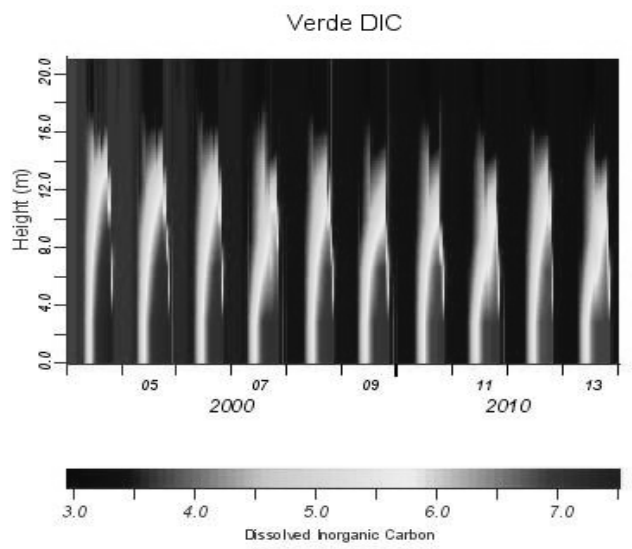

Figura 4. Resultado do comportamento do DIC na Lagoa Verde das Sete Cidades.

A diminuição do DIC ao longo dos anos, é devido ao programa de modelação considerar os lagos como sistemas fechados. Além desta condição imposta pelo modelo, que é a razão principal para que este resultado ocorra, as condições intrínsecas do lago, particularmente, o estado trófico, contribui naturalmente para o decréscimo do DIC evidenciado.

Relativamente ao ciclo anual deste elemento (DIC), como se verifica na figura 4, reflecte um comportamento coerente com os resultados verificados em campo. No período do ano mais frio e em que não se regista estratificação da coluna de água induzida pela diferença de densidade de 
origem térmica, a concentração do carbono na água é homogeneizada devido à dinâmica existente neste sistema, permitindo, mais facilmente, a troca deste elemento entre a atmosfera e a superfície da água.

$\mathrm{Na}$ época do ano em que se regista uma subida da temperatura do ar e, naturalmente, a subida da temperatura da água do lago, ocorre o aparecimento da estratificação da coluna de água de origem térmica. Uma vez que esta estratificação impede a mistura da água entre o epilimnion e o hipolimnion, o dióxido de carbono no fundo do lago é, naturalmente, retido e a sua concentração aumenta, como patenteia o resultado apresentado pelo modelo.

$\mathrm{O}$ resultado da simulação relativamente à concentração e comportamento do carbono inorgânico dissolvido é congruente com o resultado deste elemento nos lagos localizados nas zonas temperadas do hemisfério norte e que reflectem alguns problemas na qualidade da água, nomeadamente, o estado de eutrofização que se regista de uma forma mais ou menos desenvolvida (Wetzel, 1993; Berner e Berner, 1996).

No entanto, os valores de DIC apresentados pelo modelo ficam aquém dos resultados obtidos nas várias amostragens efectuadas neste lago ao longo dos últimos anos.

Se compararmos estes resultados de $\mathrm{CO}_{2}$ com os obtidos nos lagos da ilha do Pico e das Lagoas da Caldeira da Lomba e da Rasa (mínimo $=1,4$ $\mathrm{mg} / \mathrm{L}$, máximo $=10 \mathrm{mg} / \mathrm{L}$ ), na ilha das Flores, lagos em que o processo que controla o quimismo da água reflecte a contaminação destes sistemas por sais de origem marinha, através do transporte atmosférico (Antunes et al., 2007ab, Antunes, 2008), os teores de dióxido de carbono que estes lagos apresentam em profundidade estão na mesma ordem de grandeza dos simulados pelo programa DYSREM_CAEDYM.

Uma vez que o modelo não contempla qualquer influência de origem vulcânica, nomeadamente, a concentração e dinâmica deste elemento neste sistema, depreende-se que a maior concentração de $\mathrm{CO}_{2}$ registada no lago poderá ter origem na contaminação da água por este fenómeno natural, como sugerem os últimos estudos efectuados por Antunes (2003), Antunes e Cruz (2005), Cruz et al. (2006) e Antunes 2008.

Assim, é possível analisar o resultado do modelo sob duas perspectivas a designar: (1) o resultado da modelação efectuada vai ao encontro das conclusões apresentadas nos últimos estudos efectuados nestes sistemas lacustres, no sentido em que a diferença de concentração existente entre o modelo e os dados de campo reflectem a contribuição de origem vulcânica no quimismo da água; (2) os resultados das lagoas da ilha das Flores e do Pico, relativamente à concentração do $\mathrm{CO}_{2}$ ao longo da coluna 
de água, permitem sugerir que os valores de $\mathrm{CO}_{2}$ da lagoa Verde deveriam ocorrer na ordem de grandeza dos resultados da modelação. Deste modo, é possível diferenciar estes resultados uma vez que contribuem para a validação do modelo utilizado.

$\mathrm{O}$ resultado da primeira simulação efectuada relativa à entrada de carbono inorgânico com a menor concentração $(500 \mathrm{mg} / \mathrm{l})$ e durante o menor período de tempo (1 mês) reflecte um ligeiro aumento do DIC no início do ano de 2004 (Figura 5). Uma vez que o incremento deste elemento acontece no mês de Janeiro, altura do ano em que os fenómenos meteorológicos são mais extremos, como já referido anteriormente, a maior intensidade do vento aliada a temperaturas mais baixas induzem uma dinâmica nestes lagos que permite uma rápida mistura do carbono na água e a sua difusão para a atmosfera. Assim, verifica-se uma rápida atenuação da entrada de carbono no lago, à qual não é indiferente o maior volume de água neste sistema lacustre.

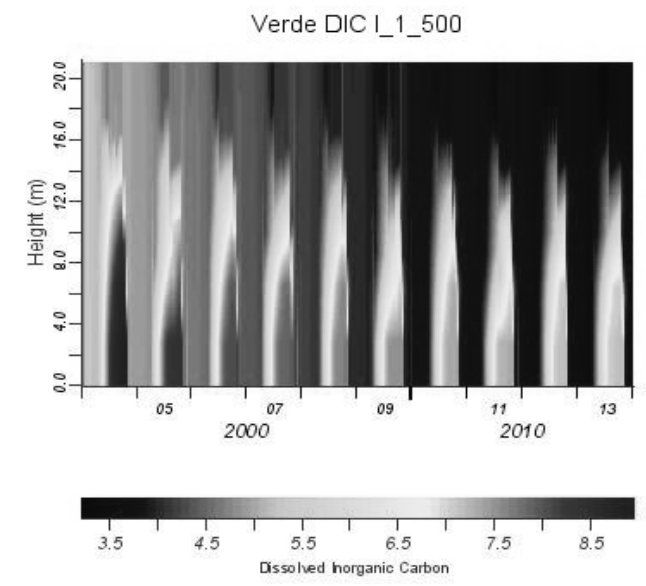

Figura 5. Resultado do input de DIC simulado no lago para o mês de Janeiro.

Relativamente à entrada de DIC durante os 184 dias de Inverno (I_6_500, I_6_2000), a configuração dos cenários altera-se (Figura 6). Como é expectável, a concentração do carbono inorgânico dissolvido aumenta consideravelmente apresentando valores 7 vezes superiores aos anteriores.

Como já discutido para os cenários anteriores relativos à lagoa Verde, é notória nestas simulações a crescente concentração do DIC. No entanto, o aspecto que se destaca de imediato na análise destes resultados radica na dispersão do carbono ao longo da coluna de água. As 3 simulações 
efectuadas apresentam uma configuração semelhante, com excepção para a concentração do carbono na água, que apresenta um aumento da sua concentração, consoante a concentração de $\mathrm{CO}_{2}$ do input. A entrada deste composto decorre entre os dias 1 de Janeiro e 30 de Junho, coincidindo com a estratificação da água deste lago, que tem início no mês de Maio. Assim, verifica-se que o DIC retido no hipolimnion durante o período de estratificação da água devido à diferença de densidade de origem térmica se acumula junto ao metalimnion, com concentrações que variam entre os $22 \mathrm{e}$ $75 \mathrm{mg} / \mathrm{l}$ entre os 7 e os $11 \mathrm{~m}$ de profundidade, nos 3 cenários simulados.

Verde DIC I_6_500

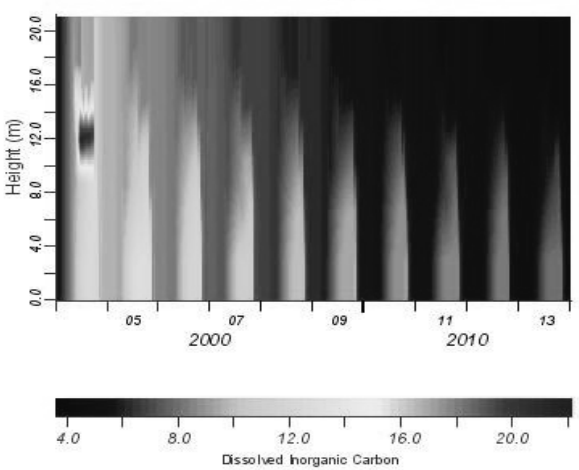

Verde DICI_6_2000

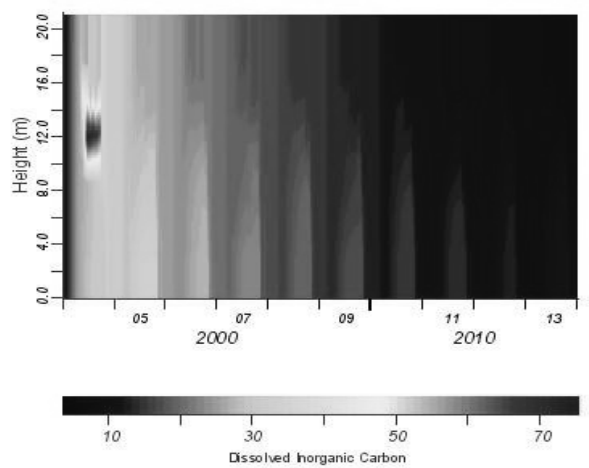

Figura 6. Resultado do input de DIC simulado, na Lagoa Verde, para os primeiros 184 dias do ano de 2004.

Após o desaparecimento da estratificação da água de origem térmica, há uma rápida diminuição da concentração do DIC e sua mistura ao longo da coluna de água. No entanto, a lagoa não recupera totalmente a concentração de carbono inicial.

As simulações efectuadas no Verão, neste lago, apresentam um resultado semelhante entre si. Como se observa na Figura 7, a concentração do DIC aumenta, consoante o aumento da concentração do carbono no input e do tempo em que decorre a entrada deste caudal nos lagos. É possível constatar o aumento significativo da concentração do carbono na simulação V_6_2000. Após o esbatimento da estratificação da água de origem térmica no ano de 2004, a concentração do DIC retido no hipolimnion rapidamente sai do lago através das trocas gasosas atmosfera/água e é notório o decréscimo substancial do carbono na água do lago a partir do ano de 2006. 
Verde DIC V_1 500

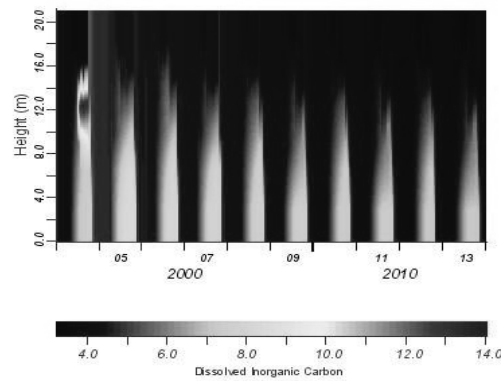

Verde DIC V_1_2000

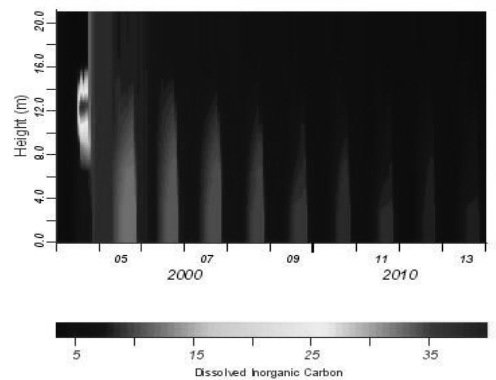

Verde DIC V_3_1000

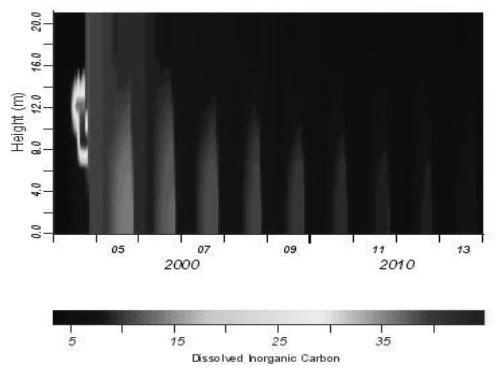

Verde DIC V_6_1000

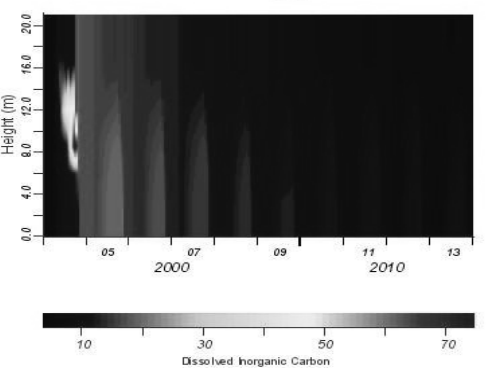

Verde DIC V_1_1000

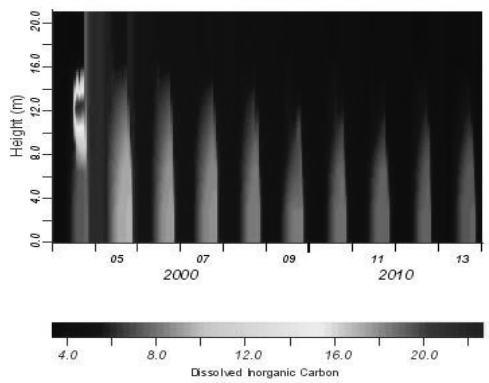

Verde DIC V_3_500

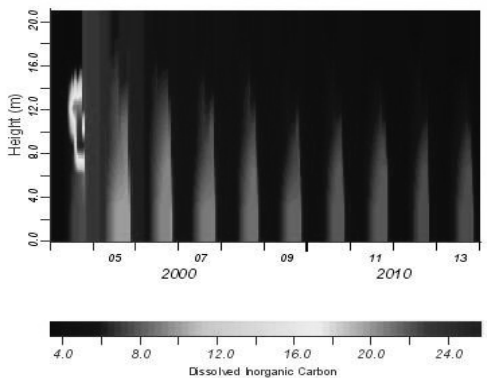

Verde DIC V_3_2000

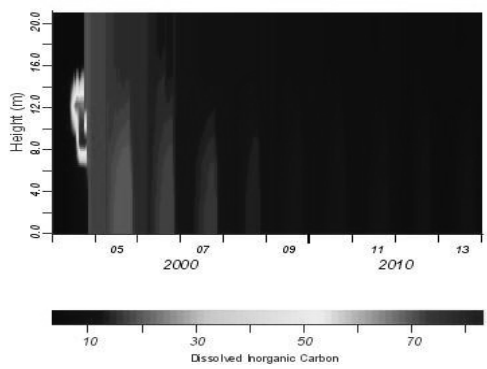

Verde DIC V_6_2000

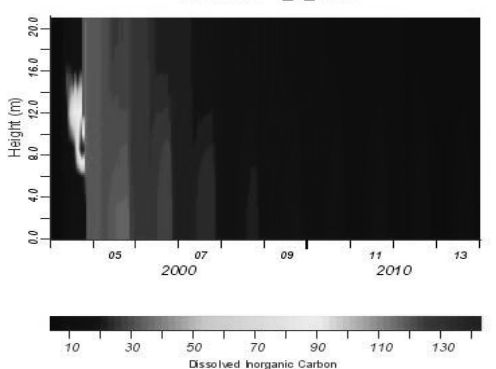

Figura 7. Resultado do input de DIC simulado, na Lagoa Verde, no período do Verão. 


\section{Conclusão}

A opção pelo modelo DYREM_CAEDYM, face aos resultados obtidos, revelou-se ter sido uma escolha acertada, devido o modelo permitir desenvolver o estudo sobre a parte hidrodinâmica dos lagos.

Os cenários simulados para as condições iniciais de cada lagoa apresentam uma diminuição do carbono orgânico dissolvido ao longo dos 10 anos modelados. Esta situação ocorre devido ao programa considerar os lagos sistemas fechados. Deste modo, o modelo tende a encontrar uma situação de equilíbrio relativamente ao carbono para valores que correspondem à dinâmica de cada sistema lacustre, uma vez que os valores iniciais configurados no programa correspondem aos dados de campo.

Este resultado, associado aos estudos efectuados nos últimos anos por Antunes (2003), Antunes e Cruz (2005), Cruz et al., (2006) e Antunes (2008), reforçam as conclusões desenvolvidos nestes sistemas, no sentido que a concentração do dióxido de carbono não provém unicamente dos processos biológicos que aí decorrem, mas que existe uma contribuição de origem vulcânica. Desta forma, estes resultados contribuem para a validação do modelo utilizado.

No primeiro cenário simulado, para o menor input e concentração de DIC inferior, depreende-se que o lago apresenta alterações no quimismo da água e que são mais evidentes com o aumento das diferentes entradas simuladas.

Em relação aos restantes cenários, as simulações foram efectuadas entre os meses de Abril e Setembro, altura do ano que, de uma forma geral, se regista estratificação da água dos lagos de origem térmica. Devido a parte dos inputs serem retidos nesta camada de água, os cenários apresentam outra configuração.

A acumulação do carbono inorgânico dissolvido na água no topo do hipolimnion verificado na Lagoa Verde, teoricamente, não faz sentido, ao considerarmos o hipolimnion isolado da superfície. A explicação mais plausível para compreender estes resultados prende-se com a configuração dos dados introduzidos no modelo.

Centrando a análise dos cenários simulados unicamente no ano de 2004, verifica-se que os resultados dos cenários Verde DIC_I_6_1000 apresentaram concentrações de carbono na coluna de água na ordem de grandeza das concentrações verificadas no campo. Assim, os dados sugerem que existe um contributo de 182 T/ano na Lagoa Verde. Contudo, estes 
valores são meramente indicativos, uma vez que dizem respeito à entrada de carbono durante 91 e 182 dias, respectivamente.

O modelo revelou-se eficiente relativamente ao objectivo do estudo planeado à partida e demonstra uma grande valência na sua utilização. $\mathrm{Na}$ presença de uma série de dados meteorológicos mais robustos, o modelo revela capacidade de simular o aparecimento e o término efectivo da estratificação da água.

No entanto, o modelo é limitado no estudo da Hidrogeoquímica nestes sistemas, não sendo possível modelar o contributo de voláteis nos sistemas aquáticos ou tirar qualquer ilação relativamente aos processos de interacção água-rocha, nomeadamente na lixiviação dos metais alcalinos e alcalino-terroso e do silício que, ao entrar na água, poderia ser modelado no sentido de averiguar o seu impacte, especificamente nas diatomaceas que incorporam a sílica na sua estrutura interna.

Contudo, ressalva-se o desenvolvimento do programa no sentido de estudar unicamente a ecologia dos sistemas aquáticos. $\mathrm{O}$ facto de ter sido possível desenvolver este estudo prova a valência do modelo.

Deste modo, o programa DYRESM-CAEDYM apresenta potencial na aplicação e exploração na monitorização vulcânica, nomeadamente, no que diz respeito a possíveis alterações hidrogeoquímicas induzidas pelo input de fluidos de origem vulcânica, assim como a possível alteração ecológica destes sistemas devido a este fenómeno. Consequentemente, também poderá contribuir para uma melhor compreensão acerca dos sistemas vulcânicos existentes nestes locais e, possivelmente, constituirá mais uma ferramenta ao dispor da monitorização vulcânica.

\section{Bibliografia}

Antunes, P (2003) - Lagos Vulcânicos dos Açores: Caracterização geoquímica e monitorização vulcanológica. Dissertação apresentada à Universidade dos Açores para efeito de obtenção do Grau de Mestre em Vulcanologia e Riscos Geológicos; Universidade dos Açores, Ponta Delgada, 99p.

Antunes, P., Cruz, J. V. (2005) - Estudo hidrogeoquímico em lagos vulcânicos dos Açores: perfis realizados nos lagos da ilha de São Miguel. Comunicações Geológicas; t. 92, 79-106.

Antunes, P., Cruz, J. V., Freire, P., Coutinho, R. (2007a) - Hydrogeochemistry of volcanic lakes from Flores island (Azores, Portugal): preliminary data. Abstract Book, ISSN: 1029-7006. General Assembly 2007 - European Geosciences Union. Viena, Áustria.

Antunes, P., Cruz, J. V., Freire, P., Coutinho, R. (2007b) - Estudo Hidrogeoquímico dos Lagos Vulcânicos da Ilha do Pico (Açores). Livro de Resumos da XV semana - VI Congresso Ibérico de Geoquímica; Trás-os-Montes, 199.

Antunes, P. (2008) - Estudo hidrogeoquímico e vulcanológico de lagos no arquipélago dos Açores: aplicações para a mitigação de riscos naturais. Dissertação apresentada à Universidade dos Açores para efeito de obtenção do Grau de Doutor em Geologia; Universidade dos Açores: Ponta Delgada, 306p. 
Balistrieri, L. S., Tempel, R. N., Stillings, L. L., Shevenell, L. A. (2006) - Modelling spatial and temporal variations in temperature and salinity during stratification and overturn in Dexter Pit Lake, Tuscarora, Nevada, USA. Applied Geochemistry; 21, 1184-1203.

Burger D. F., Hamilton, D. P., Pilditch, C. A. (2008) - Modelling the relative importance of internal and external nutrient loads on water column nutrient concentrations and phytoplankton biomass in a shallow polymictic lake. Ecological Modelling; 211, 411-423

Canfield, J. D., Hoyer, M. V. (1988) - Influence of nutrient enrichment and light availability on the abundance of aquatic macrophytes in Florida streams. Canadian Journal of Fisheries \& Aquatic Sciences; 45, 1467-1472

Copetti, D., tartari, G., Morabito, G., Oggioni, A., Legnani, E., Imberger, J. (2006) - A biogeochemical modelo f Lake Pusiano (North Italy) and its use in the predictability of phytoplankton blooms: first preliminary results. Journal limnology; 65(1), 59-64.

Cruz, J. V., Antunes, P., Amaral, C., França, Z., Nunes, J. C. (2006) - Volcanic lakes of the Azores archipelago (Portugal): Geological setting and geochemical characterization. Journal of Volcanology and Geothermal Research; 156, 135-157.

Gal, G., Imberger, J., Zohary, T., Antenucci, J., Anis, A., Rosenberg, T. (2003) - Simulating the thermal dynamics of Lake Kinneret. Ecological Modelling; 162, 69-86.

Hamilton, D. P., Schladow, S. G. (1997) - Prediction of water quality in lakes and reservoirs. Part I Model description. Ecological Modelling; 96, 91-110.

Hornung, R. (2002) - Numerical Modelling of Stratification in Lake Constance with the 1-D hydrodynamic model DYRESM. Dissertação para a obtenção do grau de Mestre; Universidade de Stuttgart, Stuttgart, 101p.

Imberger, J., Patterson, J. C., Hebbert, B., Loh, I. (1978) - Dynamics of reservoir of medium size. Jounal of Hydraulics Division I; 104, 725-743.

Imberger, J., Patterson, J. C. (1990) - Physical limnology. Adv. in Applied Mech; 27, 303-475.

Jørgensen, S. E. (1995) - State-of-the-art management models for lakes and reservoirs. Lakes \& Reservoirs: Research \& Management 1 (2): 79-87. http://www.blackwellsynergy.com/doi/abs/10.1111/j.1440-1770.1995.tb00009.x

Martins, G., Ribeiro, D. C., Pacheco, D., Cruz, J. V., Cunha, R., Gonçalves, V., Nogueira, R., Brito, A. G. (2008) - Prospective scenarios for water quality and ecological status in Lake Sete Cidades (Portugal): The integration of mathematical modelling in decision processes, Applied Geochemistry (2008); 23, 2171-2181p.

Romero, J. R., Antenucci, J. P., Imberger, J. (2004) - One and three-dimensional biogeochemical simulations of two differing reservoirs. Ecological Modelling; 174, 173-160.

Schladow, S. G., Hamilton, D. P. (1997) - Prediction of water quality in lakes and reservoirs: Part II Model calibration, sensitivity analysis and application. Ecological Modelling; 96, 111-123.

Wetzel, R. G. (1993) - Limnologia. Fundação Calouste Gulbenkian; Lisboa, 407p. 